\title{
Comparison of the superelasticity of different nickel-titanium orthodontic archwires and the loss of their properties by heat treatment
}

\author{
Humberto Bellini $^{1} \cdot$ Javier Moyano $^{1} \cdot$ Javier Gil $^{1} \cdot$ Andreu Puigdollers $^{1}$
}

Received: 27 June 2016 / Accepted: 11 August 2016 / Published online: 13 September 2016

(C) Springer Science+Business Media New York 2016

\begin{abstract}
The aim of this work is to describe and compare mechanical properties of eight widely used nickel-titanium orthodontic wires under uniform testing conditions and to determine the influence of the heat treatments on the loss of the superelasticity. Ten archwires from two batches from eight different manufacturers were evaluated. A three-point bending test was performed, in accordance with ISO 15841:2006, on 80 round nickel-titanium archwire segments of 0.016 inch. To obtain a load-deflection curve, the centre of each segment was deflected to $3.1 \mathrm{~mm}$ and then unloaded until force became zero. On the unloading curve, deflection at the end of the plateau and forces delivered at that point, and at 3,2, 1 and $0.5 \mathrm{~mm}$ of deflection, were recorded. Plateau slopes were calculated from 3 and from 2 $\mathrm{mm}$ of deflection. Data obtained were statistically analysed to determine inter-brand, intra-brand and inter-batch differences $(P<0.05)$. The results show that at $2 \mathrm{~mm}$ of deflection, maximum differential force exerted among brands [Nitinol SuperElastic (1.999N)—Sentalloy M (1.001 N)] was $0.998 \mathrm{~N}$ (102 gf). The Nitinol SuperElastic plateau slope $(0.353 \mathrm{~N} / \mathrm{mm})$ was the only one that was statistically different from $2 \mathrm{~mm}$ of deflection, as compared with the other brand values $(0.129-0.155 \mathrm{~N} / \mathrm{mm})$. Damon Optimal Force described the gentlest slope from $3 \mathrm{~mm}$ of deflection $(0.230 \mathrm{~N} / \mathrm{mm})$ and one of the longest plateaus. Titanol and Orthonol showed the most notable intra-brand differences, whereas inter-batch variability was significant for Nitinol (Henry Schein), Euro Ni-Ti and Orthonol.
\end{abstract}

Andreu Puigdollers

apuigdollersp@gmail.com

1 Department of Orthodontics, School of Dentistry, Universitat Internacional de Catalunya, Sant Cugat del Vallés,

Barcelona 08195, Spain
Superelasticity degree and exerted forces differed significantly among brands. Superelasticity of Nitinol SuperElastic was not observed, while Damon Optimal Force and Proclinic Ni-Ti Superelástico $(\mathrm{G \& H})$ showed the most superelastic curves. Intra-brand and inter-batch differences were observed in some brands. In all cases, the heat treatment at $600{ }^{\circ} \mathrm{C}$ produces precipitation in the matrix. The precipitates are rich in titanium and this fact produce changes in the chemical composition of the matrix and the loss of the superelasticity. At $400{ }^{\circ} \mathrm{C}$ these precipitates are not produced and the forces delivered by the wires are very similar with wires untreated.

\section{Introduction}

A thorough knowledge of the mechanical behaviour of an orthodontic archwire is required in order to select one of suitable size and material that will provide optimal and predictable treatment results [1-4]. Many different materials for archwires as nickel-titanium (Ni-Ti), beta-titanium and stainless steel are used during an orthodontic treatment. $\mathrm{Ni}-\mathrm{Ti}$ archwires are the most used at the beginning of the treatment when more of the dental movement is needed. For this reason their outstanding clinical characteristics as flexibility and springback make them ideal for alignment and levelling the teeth.

According to Kusy [5], there are three categories of $\mathrm{Ni}-\mathrm{Ti}$ archwires, each one having its unique properties and characteristics: conventional, pseudoelastic and thermoplastic wires, the last two of these are superelastic. The first $\mathrm{Ni}-\mathrm{Ti}$ archwire, marketed as Nitinol (Unitek Corp.) in the late 60 s, stood out for its low stiffness and high springback properties that define conventional Ni-Ti archwires. Since 
then, the Ni-Ti wire has rapidly become the wire of choice for the alignment and levelling treatment stage.

The success of today's Ni-Ti archwires is due to their superelasticity and shape memory. Superelasticity is characterised by a load-deflection curve with a horizontal region during unloading, referred to as the plateau [5]. Kusy terms this nonlinear yet nonetheless elastic behaviour pseudoelasticity. These two properties are associated with phase transitions within the $\mathrm{Ni}-\mathrm{Ti}$ alloy between the martensitic and austenitic forms that may occur either by lowering temperature or by applying stress over a defined temperature range. However, superelasticity becomes evident only if the deflection/activation is high enough to induce the martensitic transformation [6-13].

Superelastic Ni-Ti archwires are designed to move teeth with light and continuous forces. A deflected archwire should behave elastically over a period of weeks to months, generating a wide range of activation as authentic deposits of mechanical energy. Superelasticity allows the tooth to receive as constant a force as possible above a minimum required force [4-6]. If the force level remains above the physiological minimum required to induce tooth movement almost all the way to total deactivation, a full levelling should be achieved without frequent archwire changes. Furthermore, the maximal exerted force is limited, thus preventing undesirable effects such as patient discomfort, tissue hyalinisation and root resorption [14-19].

At present, there are hundreds of wire brands available. Moreover, some manufacturers do not specify the mechanical properties of their archwires. Even when the properties are specified, they usually cannot be properly compared with those of similar products due to different measuring conditions. Additionally, depending on the manufacturing process, superelastic $\mathrm{Ni}-\mathrm{Ti}$ orthodontic wires do not all have the same characteristics. Hence, some clinicians expect the same results when using wires from different brands, or even from different batches from a single manufacturer.

Some studies have reported significant differences in $\mathrm{Ni}-\mathrm{Ti}$ archwire behaviour, which often deviates from superelasicity. The differences lie in the shape of the forcedeflection curve and the position and level of the superelastic plateau [13, 14, 20]. Furthermore, differences among wires from a single brand have been reported in the literature $[11,13,18,21]$. To the authors' knowledge, only one study has been carried out in accordance with the International Norm ISO15841:2006, which specifies the requirements for the presentation of the physical and mechanical properties of orthodontic wires, the test methods by which they can be determined, the packaging and labelling of information [22].

Nowadays, it is a quite a common practice by some orthodontists to modify the arch of the Ni-Ti wires. For this shape modification, a heat treatment is applied at temperatures between 400 and $600{ }^{\circ} \mathrm{C}$. However, since the clinical performance of the orthodontic archwires is associated to the transformation temperatures and stresses, which could be affected by the thermal treatment, it is of paramount importance to assess if this thermal treatment effectively restores the thermomechanical properties of the archwires.

Therefore, the aim of this study was to evaluate and compare the mechanical properties of eight widely used orthodontic Ni-Ti archwires, independently of trade houses and under the same standardised testing conditions (International Norm ISO15841:2006). The consistency of the mechanical properties among wires from the same brand and between wires from different batches from the same manufacturer was compared. Additionally, the effect of the thermal treatments on the mechanical behaviour and the microstructure of Ni-Ti archwires of different compositions was studied.

\section{Materials and methods}

Preformed Ni-Ti alloy orthodontic wires commercialised by eight different manufacturers as superelastic with a 0.016 inch round section were assessed. Five randomly chosen wires from each two batches from each of the eight manufacturers were selected. One of the two posterior sections from each archwire was cut and tested. Thus, the total sample amounted to 80 distal sections of $40 \mathrm{~mm}$ [22]. The respective manufacturers were not informed that these materials would be studied. Table 1 shows the list of the tested archwires. The samples were distributed in tubes according to batches and then heated at a constant temperature of $36.0^{\circ} \mathrm{C}\left( \pm 1^{\circ} \mathrm{C}\right)$ for $18 \mathrm{~h}$.

A three-point bending test was performed in accordance with paragraph 6.4.3 of ISO15841:2006 regarding orthodontic wires [22]. The procedure was conducted at a constant room temperature of $36.0^{\circ} \mathrm{C}\left( \pm 1^{\circ} \mathrm{C}\right)$ under identical testing conditions using the $5 \mathrm{kN}$ QUASAR5 Universal Testing Machine (GALDABINI, Varese, Italy) [13, 22].

The mechanical properties were assessed by three-point bending tests using a $10 \mathrm{~mm}$ span of the beam $[14,22]$. The distance between the penetrator point and the two supporting points was identical. The radius of supporting and penetrator points were $0.10 \pm 0.05 \mathrm{~mm}$, in accordance with the ISO14841:2006 [22].

One test was carried out on each sample. The centre of the wire segment was deflected at a crosshead speed of 7.5 $\mathrm{mm} / \mathrm{min}$ until $3.1 \mathrm{~mm}$ of deflection in accordance with the ISO14841:2006 [22]. The degree of deflection was similar to how is produced under clinical conditions when arcades are being levelled and aligned [23]. Then the samples were unloaded at the same crosshead speed until the released force became zero. 
Table 1 Archwire groups distributed by brands and batches

\begin{tabular}{|c|c|c|c|c|}
\hline & Archwire & Diameter & Manufacturer & Batch \\
\hline HS-1 & \multirow[t]{2}{*}{ Nitinol Archwire } & \multirow[t]{2}{*}{0.016 inch } & \multirow[t]{2}{*}{ Henry Schein, Melville, NY, USA } & F1115634 \\
\hline HS-2 & & & & F1109603 \\
\hline DAMON-1 & \multirow[t]{2}{*}{ DAMON Optimal-Force Copper $\mathrm{Ni}-\mathrm{Ti}{ }^{\circledR}$} & \multirow[t]{2}{*}{$0.016 \mathrm{inch}$} & \multirow[t]{2}{*}{ Ormco, Glendora, CA, USA } & 12A369 \\
\hline DAMON-2 & & & & $12 \mathrm{~A} 226$ \\
\hline RMO-1 & \multirow[t]{2}{*}{ Orthonol® Nickel-Titanium } & \multirow[t]{2}{*}{0.016 inch } & \multirow[t]{2}{*}{ Rocky Mountain. Denver, CO, USA } & F1115984 \\
\hline RMO-2 & & & & F1121804 \\
\hline $3 \mathrm{M}-1$ & \multirow[t]{2}{*}{ Nitinol ${ }^{\circ}$ SuperElastic } & \multirow[t]{2}{*}{0.016 inch } & \multirow[t]{2}{*}{ Unitek. Monrovia, CA, USA } & CT4XX \\
\hline $3 \mathrm{M}-2$ & & & & DL1NX \\
\hline EURO-1 & \multirow[t]{2}{*}{ Euro Ni-Ti Opto TH Plus } & \multirow[t]{2}{*}{0.016 inch } & \multirow[t]{2}{*}{ ODS, Kisdorf, Germany } & F1122105 \\
\hline EURO-2 & & & & F1120179 \\
\hline FOR-1 & \multirow[t]{2}{*}{ Titanol®-Superelastic } & \multirow[t]{2}{*}{0.016 inch } & \multirow[t]{2}{*}{ Forestadent Pforzheim, Germany } & 05953398 \\
\hline FOR-2 & & & & 13955739 \\
\hline PRO-1 & \multirow[t]{2}{*}{ Proclinic Arco Ni-Ti Superelástico } & \multirow[t]{2}{*}{0.016 inch } & \multirow[t]{2}{*}{ G\&H Wire Co, Greenwood, IN, USA } & 144730 \\
\hline PRO-2 & & & & 144731 \\
\hline GAC-1 & \multirow[t]{2}{*}{ Sentalloy® superelastic } & \multirow[t]{2}{*}{0.016 inch } & \multirow[t]{2}{*}{ GAC, Grenoble, France } & H538 \\
\hline GAC-2 & & & & $\mathrm{H} 298$ \\
\hline
\end{tabular}

Graphworks 5 was used to draw the force-deflection diagrams with the same limits $(4 \mathrm{~N}-3.5 \mathrm{~mm})$ for each batch of archwires in order to compare their behaviour visually. Data were extracted from the unloading curve, which is instrumental in orthodontic tooth movement $[13,14]$. Six parameters were taken directly and two parameters indirectly to assess the superelasticity of the wires [13, 14, 22]:

- Force level delivered in Newtons $(\mathrm{N})$ when the deflection was $3.0 \mathrm{~mm}, 2.0 \mathrm{~mm}, 1.0 \mathrm{~mm}, 0.5 \mathrm{~mm}$ (Fdef- $3 \mathrm{~mm}$, Fdef$2 \mathrm{~mm}$, Fdef- $1 \mathrm{~mm}$, Fdef- $0.5 \mathrm{~mm}$, respectively) [22].

- Deflection of the archwire at the end of plateau in $\mathrm{mm}$ (Sp) [14].

- Minimum force level at the end of superelastic plateau in $\mathrm{N}$ (Fp) [14].

- Plateau slopes; one between $2 \mathrm{~mm}$ and Sp (Slope-2 $\mathrm{mm}$ ) and another between $3 \mathrm{~mm}$ and $\mathrm{Sp}$ (Slope- $3 \mathrm{~mm}$ ) of deflection expressed in $\mathrm{N} / \mathrm{mm}$. This measures the degree of plateau flatness; therefore, the closer the slope value is to zero, the more constant the force is. The loading and unloading curve of $\mathrm{Ni}-\mathrm{Ti}$ archwire and all evaluated parameters of the study are shown in Fig. 1.

Slope $-2 \mathrm{~mm}(\mathrm{~N} / \mathrm{g}): \frac{(\text { Fdef }-2 \mathrm{~mm}-\mathrm{Fp})}{(2-\mathrm{Sp})}$
Slope $-3 \mathrm{~mm}(\mathrm{~N} / \mathrm{g}): \frac{(\text { Fdef }-3 \mathrm{~mm}-\mathrm{Fp})}{(3-\mathrm{Sp})}$

Ten archwires for each composition were analysed as received, and 20 samples were subjected to a thermal treatment to simulate the procedure followed by the orthodontists previous to modify their shape. Specimens

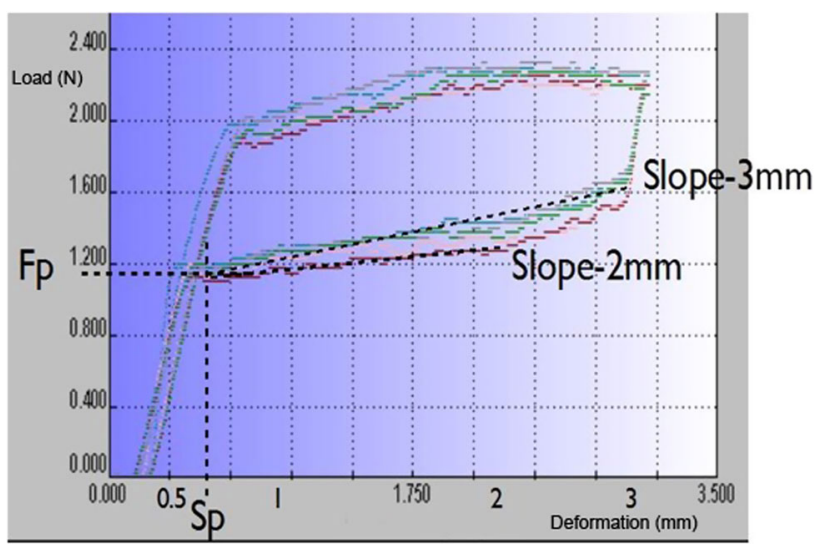

Fig. 1 Loading and unloading curve of Ni-Ti archwire and all evaluated parameters of the study

measuring $45 \mathrm{~mm}$ in length were cut from the archwires. They were heat treated in groups of five specimens at different temperatures $\left(400\right.$ and $\left.600^{\circ} \mathrm{C}\right)$ and for $1 \mathrm{~h}$. The specimens were placed in a tubular furnace with argon atmosphere at a constant temperature for each experiment and then removed from the furnace after the different periods of time and rapidly quenched in water at $20^{\circ} \mathrm{C}$.

The specimens were cut with diamond discs from pins used to carry out resistance tests. Specimens were ground with 1000 grain size paper to a thickness of $140 \mathrm{~mm}$ and electrochemically polished using a double jet thinning technique in order to observe by transmission electron microscopy (TEM). The conditions used were: $80 \%$ methanol, $20 \%$ perchloric acid electrolyte with $20 \mathrm{~V}$ of tension and electrolyte temperature of $-20^{\circ} \mathrm{C}$. The metallographic observation was carried out with a TEM using 
Table 2 Results of each brand measured variables

\begin{tabular}{|c|c|c|c|c|c|c|}
\hline Brand group & Fdef $3 \mathrm{~mm}, \mathrm{~N}(\mathrm{SD})$ & Fdef $2 \mathrm{~mm}, \mathrm{~N}(\mathrm{SD})$ & Fdef $1 \mathrm{~mm}, \mathrm{~N}(\mathrm{SD})$ & Fdef $0.5 \mathrm{~mm}, \mathrm{~N}(\mathrm{SD})$ & $\mathrm{Sp} \mathrm{mm(SD)}$ & Fp N(SD) \\
\hline HS & $2.07(.118)$ & 1.609 (.107) & $1.484(.120)$ & $1.340(.245)$ & $0.594(.105)$ & $1.428(.098)$ \\
\hline DAMON & $1.706(.092)$ & $1.356(.090)$ & $1.237(.087)$ & $1.179(.086)$ & $0.552(.045)$ & $1.138(.077)$ \\
\hline RMO & $2.093(.122)$ & $1.599(.170)$ & $1.481(.168)$ & $1.102(.399)$ & $0.708(.151)$ & $1.418(.157)$ \\
\hline $3 \mathrm{M}$ & $2.305(.093)$ & $1.999(.046)$ & $1.635(.079)$ & $0.616(.136)$ & $1.091(.214)$ & $1.639(.355)$ \\
\hline EURO & $1.816(.083)$ & $1.134(.073)$ & $1.036(.062)$ & $0.928(.054)$ & $0.474(.054)$ & $0.915(.054)$ \\
\hline FOR & $2.132(.122)$ & $1.625(.701)$ & $1.502(.050)$ & $1.138(.335)$ & $0.697(.129)$ & $1.422(.034)$ \\
\hline PRO & $1.924(.085)$ & $1.493(.077)$ & $1.376(.095)$ & $1.103(.205)$ & $0.668(.101)$ & $1.323(.094)$ \\
\hline GAC & $2.093(.085)$ & $1.001(.096)$ & $0.875(.099)$ & $0.781(.105)$ & $0.401(.048)$ & $0.772(.101)$ \\
\hline Mean (SD) & $1.954(.247)$ & $1.477(.309)$ & $1.328(.263)$ & $1.023(.309)$ & $0.648(.101)$ & $1.256(.312)$ \\
\hline$P$-value $^{\mathrm{a}}$ (Mean) & $<0.001 *$ & $<0.001 *$ & $<0.001 *$ & $<0.001 *$ & $<0.001 *$ & $<0.001 *$ \\
\hline $\boldsymbol{P}$-value $^{\mathrm{b}}(\mathrm{SD})$ & 0.820 & $<0.011^{*}$ & $<0.017 *$ & $<0.000001 *$ & $<0.001 *$ & $<0.000001 *$ \\
\hline
\end{tabular}

Mean (SD)

${ }^{\text {a }} P$-value ANOVA $95 \%$

b Bartlett's test $95 \%$

* $95 \%$ significance

a JEOL 1200 EXII Microscopy equipped with a link LZ5 EDS. The samples thermically treated were analysed by three-point bending test.

The results were analysed using Statgraphics Plus 5.1. One-way analysis of variance (ANOVA) and a $t$-test were applied to compare differences among brands and between batches, respectively. The intra-brand differences, expressed as variations on standard deviations (SD), were compared using the Bartlett's test. Statistically significant differences were observed with a $P$-value $<0.05$.

\section{Results}

\subsection{Inter-brand differences}

Table 2 shows the mean force delivered in Newtons $(\mathrm{N})$ by the different archwires at 3,2,1 and $0.5 \mathrm{~mm}$ of deflection, as well as the deflection $(\mathrm{Sp}-\mathrm{mm})$ and force delivered $(\mathrm{Fp}-\mathrm{N})$ at the end of the plateau. In the means comparison, statistical differences were observed among brands for each variable measured $(P<0.001)$.

The data reported that $3 \mathrm{M}$ archwires exerted the highest forces at all deflection points, except at $0.5 \mathrm{~mm}$, as this deflection point lay in the elastic region of their unloading curve. Besides, the pseudo-plateau of this archwire was the shortest, as it disappeared at $1.091 \mathrm{~mm}$ of deflection, while in other archwires the plateau ended between 0.401 $\mathrm{mm}$ (GAC) and $0.708 \mathrm{~mm}$ (RMO) of deflection. In contrast, GAC archwires released the lowest forces at all deflection points, except at $3 \mathrm{~mm}$, where DAMON exerted the lowest force $(1.706 \mathrm{~N})$. At $2 \mathrm{~mm}$ of deflection (close to
Table 3 Superelasticity expressed in slope- $2 \mathrm{~mm}$ and slope- $3 \mathrm{~mm}$, respectively. Ranking of superelasticity according to slope- $3 \mathrm{~mm}$

\begin{tabular}{llll}
\hline Brand group & $\begin{array}{l}\text { Plateau slope } \\
2 \mathrm{~mm}, \mathrm{~N} / \mathrm{mm} \\
(\mathrm{SD})\end{array}$ & $\begin{array}{l}\text { Plateau slope } \\
3 \mathrm{~mm}, \mathrm{~N} / \mathrm{mm} \\
(\mathrm{SD})\end{array}$ & $\begin{array}{l}\text { Superelasticity } \\
\text { ranking } \\
3 \mathrm{~mm})\end{array}$ \\
\hline HS & $0.129(.033)$ & $0.269(.037)$ & 3 \\
DAMON & $0.150(.023)$ & $0.230(.019)$ & $\mathbf{1}^{*}$ \\
RMO & $0.139(.043)$ & $0.294(.044)$ & 4 \\
3M & $\mathbf{0 . 3 5 3 ( . 2 1 8 ) *}$ & - & - \\
EURO & $0.143(.025)$ & $0.356(.030)$ & $\mathbf{7}^{*}$ \\
FOR & $0.155(.034)$ & $0.308(.046)$ & 5 \\
PRO & $0.127(.024)$ & $0.257(.035)$ & 2 \\
GAC & $0.142(.024)$ & $0.312(.025)$ & 6 \\
Mean (SD) & $0.167(.106)$ & $0.295(.069)$ & - \\
$P$-value & $<\mathbf{0 . 0 0 1 *}$ & $<\mathbf{0 . 0 0 1 *}$ & - \\
$P$-value & 0.359 & $<\mathbf{0 . 0 0 1 *}$ & - \\
$\begin{array}{l}\text { without } 3 \mathrm{M} \\
\text { group) }\end{array}$ & & & \\
\hline
\end{tabular}

* $95 \%$ significance

the centre of the plateau of all the archwire brands tested), maximum differential force exerted among brands was $0.998 \mathrm{~N}(102 \mathrm{~g})$. Values ranged between $1.999 \mathrm{~N}(3 \mathrm{M})$ and $1.001 \mathrm{~N}$ (GAC).

The degree of superelasticity was defined by the plateau slopes. The plateau was evaluated both from $2 \mathrm{~mm}$ of deactivation to the Sp point (Slope- $2 \mathrm{~mm}$ ) and from $3 \mathrm{~mm}$ of deactivation to the Sp point (Slope- $3 \mathrm{~mm}$ ). Table 3 shows the results of these measurements and the superelasticity ranking.

The slope- $2 \mathrm{~mm}$ were non-statistically different $\left(\begin{array}{l}P \\ 0.359)\end{array}\right.$ and ranged between $0.127 \mathrm{~N} / \mathrm{mm}$ (PRO) and $0.155 \mathrm{~N} / \mathrm{mm}$ 
Fig. 2 Box and whisker plot for all studied brands of archwires in 2 and $3 \mathrm{~mm}$ deformation. Test ANOVA $95 \%$
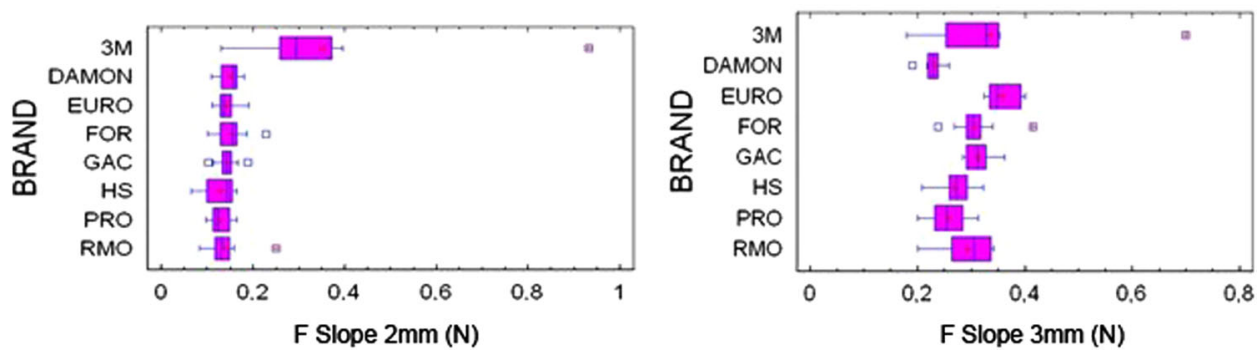

(FOR), with the exception of the slope obtained for $3 \mathrm{M}$ $(0.353 \mathrm{~N} / \mathrm{mm})$, which showed a non-superelastic behaviour between $2 \mathrm{~mm}$ of deflection and Sp. However, a comparison of slope- $3 \mathrm{~mm}$ showed differences among all the brand groups $(P<0.001)$. DAMON group $(0.230 \mathrm{~N} / \mathrm{mm})$ had the gentlest slope, while the steepest one was obtained for EURO $(0.356 \mathrm{~N} / \mathrm{mm})$.

Figure 2 illustrates the similitude of the superelastic behaviour in slope- $2 \mathrm{~mm}$ and, in contrast, the differences that appeared when the slope was measured from $3 \mathrm{~mm}$ (slop-3 mm).

Due to their superelastic properties, $\mathrm{Ni}-\mathrm{Ti}$ archwires are able to produce teeth movement with greater efficiency and in a shorter time in comparison to other orthodontic alloys; they are especially indicated in situations that require large deflections of an orthodontic archwire such as the preliminary bracket alignment stage in load deflection in orthodontic therapy.

\subsection{Intra-brand differences}

The comparison of SD can be observed in Table 2 highlighted statistical differences among intra-brand variations of all analysed measurements, with the exception of the force exerted at $3 \mathrm{~mm}$ of deflection $(P<0.001)$.

As a rule, the largest SD appeared in the force exerted at $0.5 \mathrm{~mm}$ and at the end of the plateau (Fp) $(P<0.001)$. FOR and RMO archwires showed the least reproducible behaviour, while GAC and DAMON archwires had the most consistent unloading curves, with the exception of one sample from DAMON batch 1. However, the SDs of the slopes (Table 3) were lower than those obtained for the six measurements shown in Table 2.

\subsection{Inter-batch differences}

The inter-batch variation for the six measurements was analysed by a $t$-test. Table 4 shows the results of the interbatch means comparison. Significant differences were observed only between EURO, HS and RMO batches. The most notable and most frequent differences appeared between RMO batches. No significant differences were
Table $4 P$-values for the comparison of the six measurements between both batches of the eight archwire brands

\begin{tabular}{lllllll}
\hline $\begin{array}{l}\text { Brand } \\
\text { (batch 1 } \\
\text { vs. 2) }\end{array}$ & $\begin{array}{l}\text { Def 3 } \\
\text { mm }(p- \\
\text { value })\end{array}$ & $\begin{array}{l}\text { Def 2 } \\
\text { mm }(p- \\
\text { value })\end{array}$ & $\begin{array}{l}\text { Def 1 } \\
\text { mm }(p- \\
\text { value })\end{array}$ & $\begin{array}{l}\text { Def 0.5 } \\
\text { mm }(p- \\
\text { value })\end{array}$ & $\begin{array}{l}\text { Sp }(p- \\
\text { value })\end{array}$ & $\begin{array}{l}\text { Fp }(p- \\
\text { value })\end{array}$ \\
\hline HS & 0.2298 & $\mathbf{0 . 0 0 8 6}^{*}$ & $\mathbf{0 . 0 0 0 6}^{*}$ & $\mathbf{0 . 0 1 5 0 *}$ & 0.5812 & $\mathbf{0 . 0 0 2 6}^{*}$ \\
DAMON & 0.6815 & 0.4771 & 0.8682 & 0.8666 & 0.8987 & 0.8817 \\
RMO & $\mathbf{0 . 0 3 6 6}^{*}$ & $\mathbf{0 . 0 0 0 0}^{*}$ & $\mathbf{0 . 0 0 0 0 *}^{*}$ & 0.9769 & 0.3233 & $\mathbf{0 . 0 0 0 1 *}^{*}$ \\
3M & 0.5528 & 0.8520 & 0.8548 & 0.1320 & 0.3240 & 0.4508 \\
EURO & 0.0625 & $\mathbf{0 . 0 2 8 2}^{*}$ & $\mathbf{0 . 0 1 3 3}^{*}$ & 0.1370 & 0.9160 & 0.1175 \\
FOR & 0.7048 & 0.9015 & 0.6448 & 0.3089 & 0.5433 & 0.3870 \\
PRO & 0.8382 & 0.6787 & 0.7139 & 0.6406 & 0.9096 & 0.9267 \\
GAC & 0.7870 & 0.4083 & 0.5752 & 0.3826 & 0.4258 & 0.4151 \\
\hline
\end{tabular}

* Statistically significant, $P<0.05$

* $95 \%$ significance

Table 5 Minimum force level at the end of superelastic plateau in original samples, treated at 400 and $600{ }^{\circ} \mathrm{C}$ for $1 \mathrm{~h}$

\begin{tabular}{llll}
\hline Brand group & $\begin{array}{l}\mathrm{Fp} \text { as-received } \\
\mathrm{N}(\mathrm{SD})\end{array}$ & $\begin{array}{l}\mathrm{Fp} 400{ }^{\circ} \mathrm{C} \\
\mathrm{N}(\mathrm{SD})\end{array}$ & $\begin{array}{l}\mathrm{Fp} \mathrm{600}{ }^{\circ} \mathrm{C} \\
\mathrm{N}(\mathrm{SD})\end{array}$ \\
\hline HS & $1.428(.098)$ & $1.209(.107)$ & 0 \\
DAMON & $1.138(.077)$ & $1.056(.090)$ & 0 \\
RMO & $1.418(.157)$ & $1.299(.170)$ & 0 \\
$3 \mathrm{M}$ & $1.639(.355)$ & $1.399(.046)$ & 0 \\
EURO & $0.915(.054)$ & $0.634(.073)$ & 0 \\
FOR & $1.422(.034)$ & $1.125(.701)$ & 0 \\
PRO & $1.323(.094)$ & $1.193(.077)$ & 0 \\
GAC & $0.772(.101)$ & $0.341(.096)$ & 0 \\
\hline
\end{tabular}

observed between batches regarding plateau length (Sp) for any brand.

\subsection{Heat treatments}

In Table 5 can be observed the minimum forces at the end of superelastic plateau for the as-received samples, and the treated at 400 and $600{ }^{\circ} \mathrm{C}$ for $1 \mathrm{~h}$. It can be observed that the samples treated at $400^{\circ} \mathrm{C}$ for $1 \mathrm{~h}$ presented forces at the end of superelastic plateau slightly lower than as-received 
Fig. 3 Precipitates observed by SEM located in grain boundaries. a $\mathrm{Ni}-\mathrm{Ti}$ archwire treated at $600{ }^{\circ} \mathrm{C}$ for $30 \mathrm{~min}$, b $\mathrm{Ni}-\mathrm{Ti}$ archwire treated at $600{ }^{\circ} \mathrm{C}$ for $1 \mathrm{~h}, \mathrm{c}$ Precipitate observed by TEM. The spherical morphology can be observed. d Diffraction pattern of $\mathrm{Ti}_{2} \mathrm{Ni}$ with zone axes
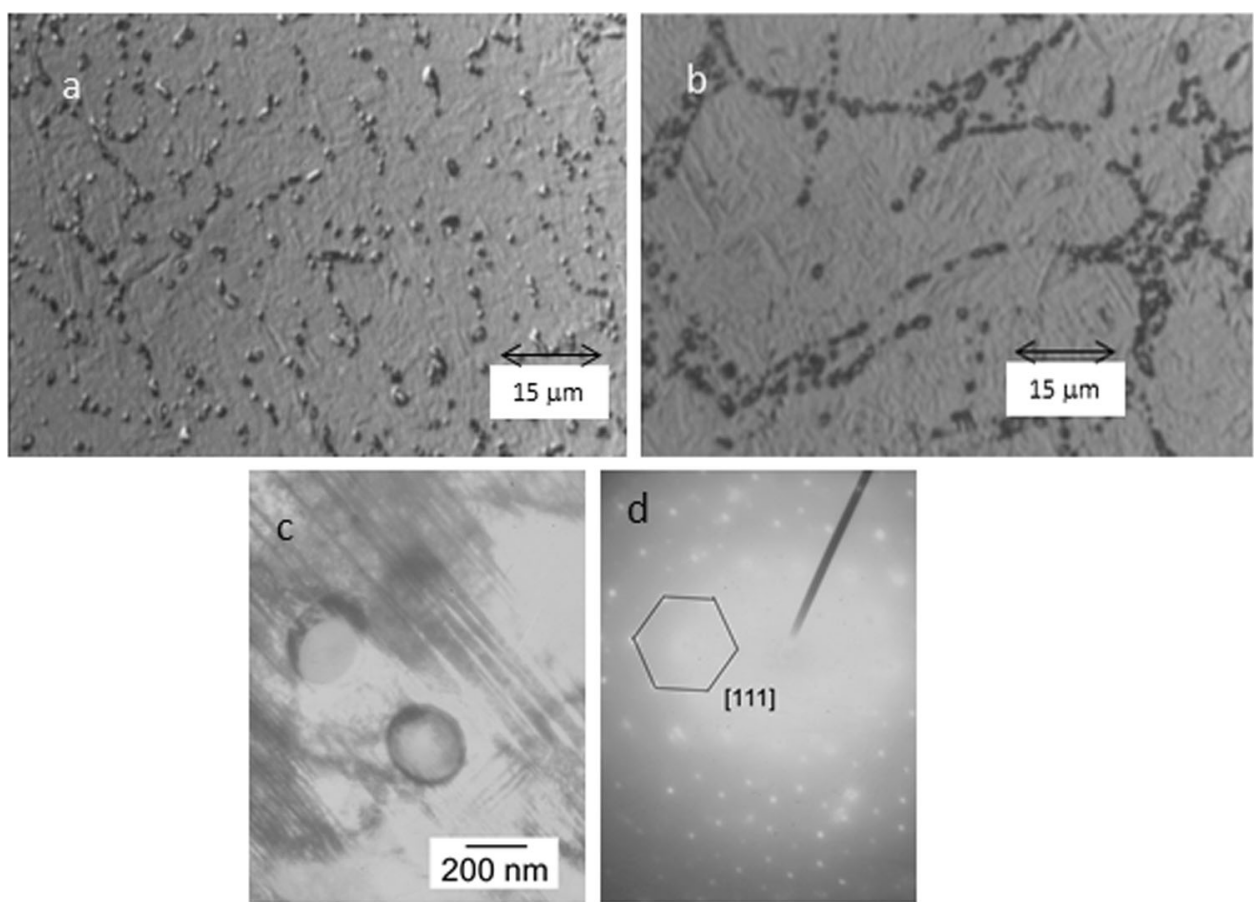

material. The samples treated at $600{ }^{\circ} \mathrm{C}$ did not present plateau.

The thermal treatment of the $\mathrm{Ni}-\mathrm{Ti}$ archwires produced different degrees of precipitation or ageing depending on the temperature and the heating time. Scanning electron microscopy (SEM) and TEM micrographs with foil plane are shown in Fig. 3 as a representative example of microstructure of the archwires treated at $600{ }^{\circ} \mathrm{C}$ where can be observed precipitates. The precipitates were not observed when the samples were treated at $400{ }^{\circ} \mathrm{C}$ for $1 \mathrm{~h}$. However, the samples treated at $600{ }^{\circ} \mathrm{C}$ produce precipitation in the grain boundaries. From Figs. $3 \mathrm{a}$ and $\mathrm{b}$ we can observe the differences between the same sample treated at $600{ }^{\circ} \mathrm{C}$ for $30 \mathrm{~min}$ or $1 \mathrm{~h}$. At $1 \mathrm{~h}$ the precipitates are more abundant with very similar sizes. For $1 \mathrm{~h}$ the precipitation can be considered finished.

The precipitates are aligned on the grain boundary, have a spherical shape and have an average diameter of $490+/-$ $203 \mathrm{~nm}$ (Fig. 3c). Therefore, these were characterised by electron diffraction technique showing a Face-Centered Cubic structure (FCC structure) with a lattice parameter of 11.278 $\AA$. The data coincides with references corresponding to $\mathrm{Ti}_{2} \mathrm{Ni}$ precipitates forming these precipitates incoherent phases with the matrix. This fact produces an increase of the interface energy producing spherical shape in order to minimise the internal energy of the system. The diffraction pattern of $\mathrm{Ti}_{2} \mathrm{Ni}$ is shown with zone axes can be observed in Fig. 3d.

These Ti-rich precipitates are very stable and the chemical composition of the matrix was determined by Energy
Dispersive Spectroscopy analysis (EDS analysis) with the TEM. The precipitates produce a decrease of the titanium content (around $0.63 \%$ ) during the thermochemical treatment into Ni-Ti bulk.

\section{Discussion}

Due to its reproducibility, the three-point bending test, first developed by Miura et al. in 1986, has become the gold standard for testing and comparing the flexural properties of orthodontic wires [6, 8, 12, 13, 18, 24, 25]. However, a number of authors have attempted to simulate some variables encountered in clinical conditions where the wire is constrained as part of a fixed appliance [11, 12, 14, 19, 26]. Yet, there appears to be no established consensus in the literature review regarding the exact test procedure of the three-point bending test [27-32]. This flexural test is currently regulated by two norms:

-European Norm EN ISO 15841:2006. Dentistry. Wires for use in orthodontics. European Committee for Standardization. Bruxelles (2006) [22].

-American National Standard/American Dental Association (ANSI/ADA). Specification no.32. Orthodontic wires: 2006 (Reaffirmed in 2010). This standard is identical to ISO 15841:2006 [33].

Nonetheless, the literature review shows that no subsequent studies have followed the ISO 15841:2006 [13, 17, 20, 27, 30, 32], except one study by Brauchli et al. [24]. Hence, this study recommends that all research should 
Fig. 4 Loading and unloading curve of all studied $\mathrm{Ni}-\mathrm{Ti}$ archwires

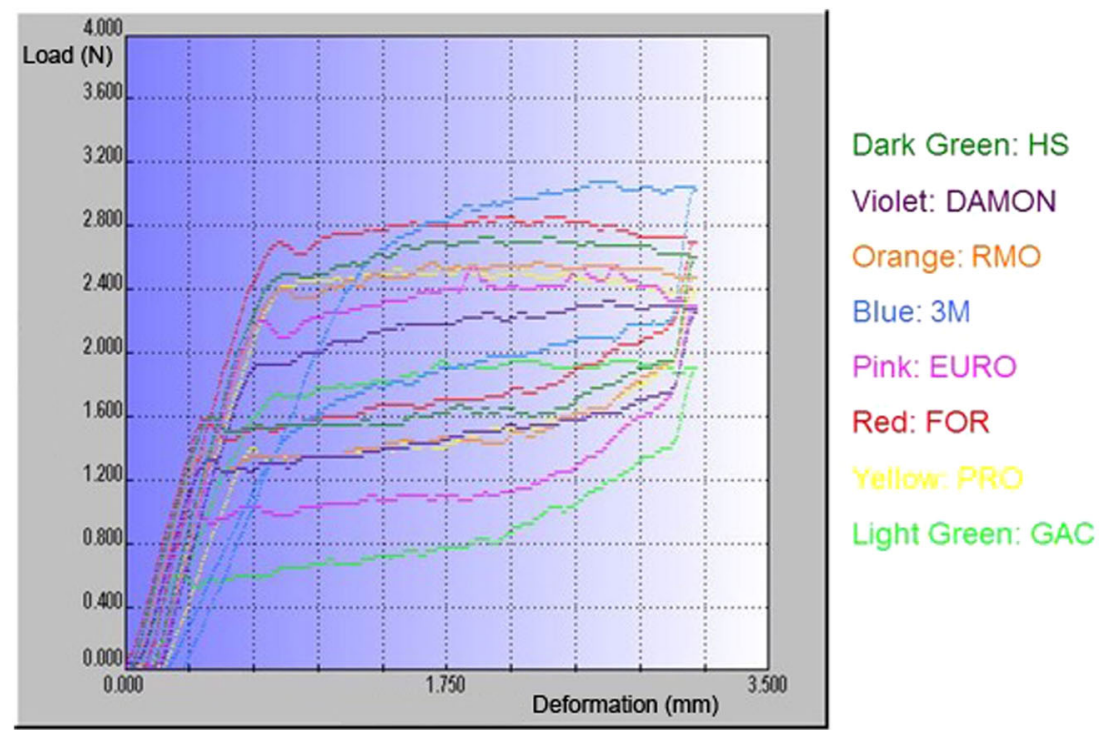

follow a single standard procedure with the same parameters (ISO 15841:2006) in order to accurately compare the properties of the different wires reported in the literature. In addition, manufacturers should define the mechanical properties of their archwires using the three-point bending test as established in the European Norm [34].

A wide variability of the load-deflection properties was observed among Ni-Ti archwires supplied by the different manufacturers, and even among different batches of wires from the same manufacturer. The analysis showed strong statistical differences among brands for all the measurements, as previously reported in other studies $[6,13,14,20]$.

\subsection{Inter-brand differences}

Figure 4 shows an overview of the different archwire behaviours. The graph shows similar curves, with an evident superelastic plateau represented by a notable difference in the slope of the unloading curve, which could be divided into two regions: an initial and longer superelastic region (martensite phase) and a final elastic region (austenite phase). The $3 \mathrm{M}$ group is the exception, due to its subtle difference between these two phases. No wire showed any permanent deformation after the three-point bending test. $3 \mathrm{M}$ had the most differentiated curve, which could be considered as non-superelastic. In this case, the plateau of the loading and unloading curve appeared and disappeared later and sooner, respectively, than the other plateaus; hence the plateau length was shorter. Furthermore, the delivered forces seemed to be much higher. The GAC group, in contrast, had the lowest delivered forces. Long plateaus and low forces seemed to be delivered by EURO and DAMON groups.
According to the data, at $2 \mathrm{~mm}$ of deflection this study observed differences of $0.998 \mathrm{~N}(102 \mathrm{~g})$ between the force delivered by Nitinol SE $(1.999 \mathrm{~N})$ and by Sentalloy M $(1.001 \mathrm{~N})$, which has a clinical impact. Nakano et al. [6] reported differences of $140 \mathrm{~g}$ in the force delivered at $2 \mathrm{~mm}$ of deflection among 19 brands of 0.016 inch round wires. However, they included both superelastic and conventional $\mathrm{Ni}-\mathrm{Ti}$ archwires. Specifically, between Sentalloy (0.784 N) and Nitinol SE $(1.441 \mathrm{~N})$, these authors reported a difference of $0.657 \mathrm{~N}$ at $2 \mathrm{~mm}$ of deflection between $14 \mathrm{~mm}$ span instead of $10 \mathrm{~mm}$, which might explain the greater difference obtained in the present study.

Tonner and Waters [31] concluded that force values at mouth temperature may differ by $600 \%$ for wires of the same nominal diameter $(0.0016 \mathrm{inch})$ made by different manufacturers. In comparison with of the force values obtained for Nitinol SE at $0.5,1,2$ and $3 \mathrm{~mm}$ of deflection with those facilitated in specifications of $3 \mathrm{M}$ Unitek, the results of the present study ranged within maximum and minimum forces delivered in the three-point bending test developed by $3 \mathrm{M}$ Unitek, in accordance with ISO 15841 [34].

The degree of superelasticity defined by the plateau slope depended on the range of deactivation ( $x$-axis) in which the slope was assessed, as observed in Table 3. While slope-2 $\mathrm{mm}$ showed only statistical differences for the $3 \mathrm{M}$ group, slope- $3 \mathrm{~mm}$ showed more evident differences. This finding was due to an increase in the slope for almost all the archwire groups between 3 and $2 \mathrm{~mm}$ of deflection, which is similar to the findings of Lombardo et al. [20].

The most superelastic behaviour was shown by the DAMON group, with a slope $-3 \mathrm{~mm}$ of $0.230 \mathrm{~N} / \mathrm{mm}$. Thus, the force exerted decreased by $0.230 \mathrm{~N}(23.5 \mathrm{~g})$ for each millimetre of deactivation. This almost constant delivered force over a wide range allows the orthodontist to engage 
the archwire even in teeth that are far from their correct position in the arcades (e.g., high canines).

In agreement with Gil [35] and Bartzela et al. [13], the addition of copper in the DAMON archwires is effective in narrowing the stress hysteresis and decreasing the slope of the unloading curve. Wilkinson et al. [11] and Lombardo et al. [20] also ranked Ormco Copper Ni-Ti $27^{\circ}$ (similar to Damon Optimal Force) as the most superelastic among 7 brands and 17 brands, respectively. Additionally, this wire also had the lowest hysteresis. This finding could suggest that lower loading forces are necessary to engage the wire in the bracket slot. In addition, Liaw et al. concluded that although friction is multifactorial, austenitic-active $\mathrm{Ni}-\mathrm{Ti}$ archwires with low-stress hysteresis might improve the sliding between the bracket and the archwire [15].

In contrast, Nitinol SuperElastic (3M) had the steepest slopes and the shortest plateau. According to the wire classification of Bartzela et al., this wire belongs to the non-superelastic group, with a clinical plateau length of $0.13 \mathrm{~mm}$ [13].

The present study ranked the FOR group in fifth place of the seven archwire brands, with a plateau slope of $0.339 \mathrm{~N} /$ $\mathrm{mm}$. According to Tonner and Waters, Titanol had no superelasticity because the slope of the unloading curve did not decrease according to their definition of plateau, which those authors consider as the region where the slope is less than or equal to $10 \mathrm{cN} / \mathrm{mm}$ of deflection [31]. According to Segner and Ibe, Titanal (FOR) and Nitinol SE (3M) were neither superelastic, nor did they have superelastic tendencies [14]. However, Bartzela et al. considered Titanal as true superelastic, with a clinical plateau longer than $0.5 \mathrm{~mm}(0.92$ $\mathrm{mm}$ ) and a mean force of $1.09 \mathrm{~N}$ [13]. Hence, there is some controversy surrounding the superelasticity of Titanol (FOR).

The controversy may be explained by the variation among studies in the region of the unloading curve along the $x$-axis where the slope was calculated. Therefore, the authors of the present study believe it is necessary to standardise the method for calculating the plateau slope. Bartzela et al. also reported that Sentalloy M (GAC) and Orthonol (RMO) had superelastic tendencies. However, the slopes they reported for these two archwires produced different results: the Orthonol's slope is much gentler $(39 \mathrm{~g} / \mathrm{mm})$ than Sentalloy's M $(173 \mathrm{~g} / \mathrm{mm})$ [14]. Similar ranking results were obtained in the present study.

The wires with longer and less pronounced clinical plateaus, such as the DAMON group, are true superelastic and provide relatively stable forces, indicating the best clinical performance. The main clinical advantage of these types of wires is their ability to apply relatively low and stable force levels for the first phase of treatment with fixed appliances. The true superelastic wires are indicated for levelling and should be especially recommended for the treatment of adult patients and stark crowding cases [13, 14].
Sentalloy M had the lowest Sp $(0.40 \mathrm{~mm})$. Its superelastic behaviour was still present until almost the end of the unloading curve. Segner et al. obtained a similar result $(0.50 \mathrm{~mm})[14]$. Thus, these archwires released a relatively constant force until the correction of almost all the crowding. Furthermore, the wires with a longer clinical plateau together with greater application forces, such as the DAMON Optimal Force (Sp: $0.552 \mathrm{~mm}$ and force at $2 \mathrm{~mm}$ : $1.356 \mathrm{~N}$ ), are indicated for derotational procedures [13].

On the other hand, in agreement with Lombardo et al. [20], the shortest pseudo-plateau of Nitinol SuperElastic with the highest $\mathrm{Sp}$ value $(1.091 \mathrm{~mm})$ is another characteristic that casts doubt on the superelasticity of this archwire.

\subsection{Intra-brand differences}

The highest SD were obtained for values of delivered forces at specific millimetres of deflection, with variations up to $\pm 0.701 \mathrm{~N}(71.5 \mathrm{~g})$ as reported for force exerted at $2 \mathrm{~mm}$ of deflection within FOR group. However, both plateau slopes values of all the archwires are highly reproducible, with the exception of the one obtained for $3 \mathrm{M}$ group, because of the difficulty to identify the end of the "pseudo-plateau" (Sp). Tonner and Waters stated that the coefficients of variation for the plateau values for the 0.016 wires tested ranged between 3.11 and $10.34 \%$ [18].

The highest variability in forces delivered among archwires from the same brand were observed for Orthonol (RMO) and Titanol (FOR), whereas the lowest intra-brand differences were obtained for the DAMON and GAC groups, in agreement with Tonner, who reported a variability of 8.04 and $3.17 \%$ for Titanol and Sentalloy M, respectively [18].

However, Bartzela et al. concluded that Ormco and Forestadent had less variability between the same type of wire products (same batch) in comparison with those of other manufacturers [13]. Besides, they established that the variability in the repeated measurements of the same type of wire reflects both the variability between individual wires and the measurement error [13].

\subsection{Inter-batch differences}

This study also reported inter-batch differences for HS, EURO and, especially, RMO group, as was advanced by Wilkinson et al. and Bartzela et al. [11, 13]. Some authors have suggested that the manufacturers should at least quantify the elastic parameters of each batch if they are unable to improve the standardisation of the mechanical properties of the wires $[16,21]$. 


\subsection{Heat treatments}

A relevant finding was that, under these circumstances, the alloy can loss partially its shape memory and superelastic properties due to the anchorage of the stress-induced martensite in the precipitates. This fact does not occur when the heat treated is at temperatures lower $400{ }^{\circ} \mathrm{C}$. It can be observed that at $400{ }^{\circ} \mathrm{C}$ decrease lightly the delivered forces but the archwire presents superelasticity. On the contrary, the samples treated at $600{ }^{\circ} \mathrm{C}$ did not present plateau and consequently the superelastic behaviour has disappeared.

However, these properties were recovered by applying a heat treatment at $900{ }^{\circ} \mathrm{C}$ for $30 \mathrm{~min}$, which was able to dissolve the precipitates.

Arciniegas et al. [36] have demonstrated the appearance of Ni-Ti precipitates rich in Titanium $\left(\mathrm{Ti}_{2} \mathrm{Ni}\right)$ when a Ni-Ti alloy (50\% at with martensitic microstructure) are subjected at similar heat treatments. $\mathrm{Ti}_{2} \mathrm{Ni}$ precipitates impeded the growth of martensitic plates and can be nucleation source of them. Similar observations were reported by Firstov et al. [37] where the martensitic transformation of the substrate $\mathrm{Ni}-\mathrm{Ti}$ alloy beneath the oxidised scale is suppressed below room temperature because of the depletion of the $\mathrm{Ni}-\mathrm{Ti}$ lattice by $\mathrm{Ti}$ which is consumed in the oxidised scale to produce Ti oxides.

\section{Conclusions}

Nitinol SuperElastic (3M) did not seem to be superelastic, while Damon Optimal Force (DAMON) showed desirable properties such as the release of light, continuous and almost constant forces during an extended period of activation. The degree of superelasticity and, above all, exerted forces differed significantly among brands. The intra-brand variability had a far greater impact on the released forces than on the length of the plateau and the degree of superelasticity. Titanol (FOR) and Orthonol (RMO) showed the least reproducible behaviours. In contrast, the unloading curves of Damon Optimal Force and Sentalloy $M$ were consistent. Significant inter-batch differences were only observed between Orthonol (RMO), Nitinol Henry Schein (HS) and Euro Ni-Ti Optho TH Plus (EURO) batches. These variations mostly appeared for force values delivered at 1 and $2 \mathrm{~mm}$ of deflection. Hence, $\mathrm{Ni}-\mathrm{Ti}$ archwires must be selected by considering the load-deflection properties in relation to the treatment stage, degree of deflection (crowding), periodontal support and type of desired movement. The heat treatments used in order to modify the original shape produce Ni-rich precipitates avoiding the superelastic properties.
Compliance with ethical standards

Conflict of interest The authors declare that they have no conflict of interest.

\section{References}

1. Juvvadi SR, Kailasam V, Padmanabhan S, Chitharanjan AB. Physical, mechanical, and flexural properties of 3 orthodontic wires: an in-vitro study. Am J Orthod Dentofacial Orthop. 2010;138(5):623-30.

2. Krishnan V, Kumar KJ. Mechanical properties and surface characteristics of three archwire alloys. Angle Orthod. 2004;74 (6):825-31.

3. Kapila S, Sachdeva R. Mechanical properties and clinical applications of orthodontic wires. Am J Orthod Dentofacial Orthop. 1989;96(2):100-9.

4. Bourauel C. Nickel-titanium alloys. Material characteristics, corrosion and biocompatibility. University of Bonn 2007.

5. Kusy RP. A review of contemporary archwires: their properties and characteristics. Angle Orthod. 1997;67(3):197-207.

6. Nakano H, Satoh K, Norris R, Jin T, Kamegai T, Ishikawa F, et al. Mechanical properties of several nickel-titanium alloy wires in three-point bending tests. Am J Orthod Dentofacial Orthop. 1999;115(4):390-5.

7. Proffit W. Mechanical principles in orthodontic force control. In: Contemporary orthodontics. 4th ed. St Louis: Mosby 2006.

8. Miura F, Mogi M, Ohura Y, Hamanaka H. The super-elastic property of the Japanese NiTi alloy wire for use in orthodontics. Am J Orthod Dentofacial Orthop. 1986;90(1):1-10.

9. Andreasen G, Heilman H, Krell D. Stiffness changes in thermodynamic Nitinol with increasing temperature. Angle Orthod. 1985;55(2):120-6.

10. Burstone CJ, Qin B, Morton JY. Chinese NiTi wire-a new orthodontic alloy. Am J Orthod. 1985;87(6):445-52.

11. Wilkinson PD, Dysart PS, Hood JA, Herbison GP. Loaddeflection characteristics of superelastic nickel-titanium orthodontic wires. Am J Orthod Dentofacial Orthop. 2002;121 (5):483-95.

12. Waters NE. Superelastic nickel-titanium wires. Br J Orthod. 1992;19(4):319-22.

13. Bartzela TN, Senn C, Wichelhaus A. Load-deflection characteristics of superelastic nickel-titanium wires. Angle Orthod. 2007;77(6):991-8.

14. Segner D, Ibe D. Properties of superelastic wires and their relevance to orthodontic treatment. Eur J Orthod. 1995;17 (5):395-402.

15. Liaw YC, Su YY, Lai YL, Lee SY. Stiffness and frictional resistance of a superelastic nickel-titanium orthodontic wire with low-stress hysteresis. Am J Orthod Dentofacial Orthop. 2007;131 (5):578.e12-578.e18.

16. Santoro M, Nicolay OF, Cangialosi TJ. Pseudoelasticity and thermoelasticity of nickel-titanium alloys: a clinically oriented review. Part II: deactivation forces. Am J Orthod Dentofacial Orthop. 2001;119(6):594-603.

17. Iijima M, Ohta M, Brantley WA, Naganishi A, Murakami T, Muguruma $\mathrm{T}$, et al. Transformation behavior of nickel-titanium orthodontic wires under tensile load. Dent Mater J. 2011;30 (3):398-403.

18. Tonner RI, Waters NE. The characteristics of super-elastic Ni-Ti wires in three-point bending. Part II: intra-batch variation. Eur J Orthod. 1994;16(5):421-5.

19. Meling TR, Odegaard J. The effect of short-term temperature changes on superelastic nickel-titanium archwires activated in 
orthodontic bending. Am J Orthod Dentofacial Orthop. 2001;119 (3):263-73.

20. Lombardo L, Marafioti M, Stefanoni F, Mollica F, Siciliani G. Load deflection characteristics and force level of nickel-titanium initial archwires. Angle Orthod. 2012;82 (3):507-21.

21. Bourauel C, Drescher D, Ebling J, Broome D, Kanarachos A. Superelastic nickel-titanium alloy retraction springs-an experimental investigation of force systems. Eur J Orthod. 1997;19 (5):491-500.

22. European Committee for Standardization. European Norm EN ISO 15841:2006. Dentistry. Wires for use in orthodontics. 2006.

23. Kusy RP, Dilley GJ. Elastic modulus of a triple-stranded stainless steel arch wire via three- and four-point bending. J Dent Res. 1984;63(10):1232-40.

24. Brauchli LM, Keller H, Senn C, Wichelhaus A. Influence of bending mode on the mechanical properties of nickel-titanium archwires and correlation to differential scanning calorimetry measurements. Am J Orthod Dentofacial Orthop. 2011;139(5): e449-54.

25. Khier SE, Brantley WA, Fournelle RA. Bending properties of superelastic and nonsuperelastic nickel-titanium orthodontic wires. Am J Orthod Dentofacial Orthop. 1991;99(4):310-8.

26. Gurgel JA, Kerr S, Powers JM, LeCrone V. Force-deflection properties of superelastic nickel-titanium archwires. Am J Orthod Dentofacial Orthop. 2001;120(4):378-82.

27. Elayyan F, Silikas N, Bearn D. Mechanical properties of coated superelastic archwires in conventional and self-ligating orthodontic brackets. Am J Orthod Dentofacial Orthop. 2010;137 (2):213-7.

28. Ramazanzadeh BA, Ahrari F, Sabzevari B, Zebarjad SM, Ahrari A. Effects of a simulated oral environment and sterilization on load-deflection properties of superelastic nickel-titaniumbased orthodontic wires. Int J Orthod Milwaukee. 2011; 22(1):13-21.

29. Wang HM, Wang BK, Ren CC, Bai YX. Properties of NiTi wires with direct electric resistance heat treatment method in three-point bending tests. Zhonghua Kou Qiang Yi Xue Za Zhi. 2011;46 (3): $168-71$.

30. Iijima M, Muguruma T, Brantley W, Choe HC, Nakagaki S, Alapati SB, et al. Effect of coating on properties of esthetic orthodontic nickel-titanium wires. Angle Orthod. 2012;82 (2):319-25.

31. Tonner RI, Waters NE. The characteristics of super-elastic Ni-Ti wires in three-point bending. Part I: the effect of temperature. Eur J Orthod. 1994;16(5):409-19.

32. Quintao CC, Cal-Neto JP, Menezes LM, Elias CN. Forcedeflection properties of initial orthodontic archwires. World $\mathrm{J}$ Orthod. 2009;10(1):29-32.

33. American National Standard/American Dental Association. Specification No. 32. Orthodontic wires: 2006. Accessed 27 May, 2012.

34. 3M Unitek. Orthodontic Wire Properties-Nitinol Archwires. ISO 15841.

35. Gil FJ, Planell JA. Effect of copper addition on the superelastic behavior of $\mathrm{Ni}-\mathrm{Ti}$ shape memory alloys for orthodontic applications. J Biomed Mater Res. 1999;48 (5):682-8.

36. Arciniegas M, Gaillard Y, Peña J, Manero JM, Gil FJ. Thermoelastic phase transformation in TiNi alloys under cyclic instrumented indentation. Intermetallics. 2009;17:784-91.

37. Firstov GS, Vitchev RG, Kumar H, Blanpain B, Van Humbeeck J. Surface oxidation of NiTi shape memory alloy. Biomaterials. 2002;23:4863-71. 